\title{
Modeling Stock Market Monthly Returns Volatility Using GARCH Models Under Different Distributions
}

\author{
Rama Krishna Yelamanchili $P h D$ \\ Associate Professor \\ Department of Finance and Accounting \\ ICFAI Business School, IFHE-Hyderabad \\ Hyderabad, Telangana, India \\ Email: yrk@ibsindia.org
}

\begin{abstract}
This papers aims to uncover stylized facts of monthly stock market returns and identify adequate GARCH model with appropriate distribution density that captures conditional variance in monthly stock market returns. We obtain monthly close values of Bombay Stock Exchange's (BSE) Sensex over the period January I99I to December 2019 (348 monthly observations). To model the conditional variance, volatility clustering, asymmetry, and leverage effect we apply four conventional GARCH models under three different distribution densities. We use two information criterions to choose best fit model. Results reveal positive Skewness, weaker excess kurtosis, no autocorrelations in relative returns and log returns. On the other side presence of autocorrelation in squared log returns indicates volatility clustering. All the four GARCH models have better information criterion values under Gaussian distribution compared to $t$-distribution and Generalized Error Distribution. Furthermore, results indicate that conventional GARCH model is adequate to measure the conditional volatility. GJR-GARCH model under Gaussian distribution exhibit leverage effect but statistically not significant at any standard significance levels. Other as ymmetric models do not exhibit leverage effect. Among the I2 models modeled in present paper, GARCH model has superior information criterion values, log likelihood value, and lowest standard error values for all the coefficients in the model.
\end{abstract}

\section{Keywords: Stock Market Returns, Stylized Facts, Volatility Models, Leverage Effect, Asymmetric Model.}

\section{Introduction}

The key characteristics usually we find in asset returns are, high kurtosis, high Skewness, volatility clustering, asymmetry, and leverage effect. The Generalized Autoregressive Conditional Heteroscedastic (GARCH) model of Bollerslev (I986) is helpful to capture the leptokurtic nature of asset returns and volatility clustering and also helps to model varying conditional volatility in asset returns. On the other side asymmetric GARCH models like GJR-GARCH of (Glosten et al., I993) Exponential GARCH of (Nelson, 199I) and Asymmetric Power ARCH (APARCH) of (Ding et al., I993) captures asymmetry in returns series and the leverage effect.

The aim of present paper is to exemplify volatility models by their efficiency to capture stylized facts of India's benchmark stock market index i.e., Sensex monthly returns. Similar research is conducted in the Indian context by few researchers like (Karmakar, 2007) who report leverage effect, volatility clustering, and high persistence in Indian stock market during the period 1990-2004. Similarly (Mittal et al., 2012) report negative Skewness, high kurtosis, fat-tailed non-normal distribution, high persistence in volatility, presence of leverage effect. They suggest GARCH model for symmetric effects and PARCH model for asymmetric effects. In another context (Joshi, 20I4) using three different models over the period 20I0-20I4 analyze Sensex and report mean reverting behavior, volatility clustering, persistence, and presence of leverage effect. This paper differ extant literature in multiple perspectives. First, we consider very long time period spread over 29 years. Second, we build symmetric and asymmetric GARCH models under different distributions. Third, we compare adequacy of each GARCH model under different distribution, and also among symmetric and asymmetric models. Finally, we apply robust information criterions to select the best fit model.

We estimate GARCH (I,I), GJR-GARCH (I,I), EGARCH (I,I), and APARCH (I,I) models together with three different distribution density functions for a total of 12 models. In this paper we evaluate GARCH models using the Gaussian distribution, Student $t$-distribution, and Generalized Error Distribution (GED). We apply two different information criterions to compare symmetric and asymmetric models. The first one is Akaike Information Criterion (AIC) (Akaike, I974) and the second is Bayesian Information Criterion (BIC) (Schwarz, 1978). In addition, we also consider log likelihood ratio. We also use 
Ljung-Box Q-statistics for the $\mathrm{Q}(5), \mathrm{Q}(\mathrm{I0})$ and $\mathrm{Q}(20)$ of the standardized residuals and squared standardized residuals to test for serial correlations and residual GARCH effects.

Our results suggest that symmetric and asymmetric GARCH models under Gaussian distribution outperform GARCH models under two other distributions i.e., student's $t$-distribution and GED distribution. The conventional GARCH model has better information criterion values than asymmetric models suggesting that traditional GARCH model is adequate to capture conditional volatility of Sensex monthly returns series. We find leverage effect only in GJR-GARCH model with Gaussian distribution.

The paper is structured as follows. In Section II, we explain the data and methodology. In Section III, we present preliminary analysis. In Section IV we discuss empirical results. Finally, Section V draws conclusion.

\section{Data and Methodology}

In this paper we examine which distribution process is appropriate to model conditional volatility of Sensex monthly returns with different GARCH family models. In addition, we try to determine which of the GARCH family models is effective to capture conditional variance of Sensex monthly returns series. For the purpose of this paper, monthly close values of BSE Sensex (Sensex) are used for the period January I99I to December 2019 totaling to 347 monthly return observations. Monthly close values of Sensex come from the Bombay Stock Exchange official website (www.bseindia.org). We use returns of monthly stock index values

$$
\mathrm{r}_{\mathrm{t}}=\mathrm{IOO} \ln \left(\mathrm{P}_{\mathrm{t}} /\left(\mathrm{P}_{\mathrm{t}-\mathrm{I}}\right)\right.
$$

Where, $\mathrm{P}_{\mathrm{t}}$ is the closing value of the index at month $\mathrm{t}$.

GARCH Model

The most popular conventional volatility model is the GARCH model proposed by Bollerslev (I986). The standard GARCH(I,I) model is given by

$$
\sigma_{\mathrm{t}}^{2}=\alpha_{0}+\alpha_{1} \varepsilon_{\mathrm{t}-\mathrm{I}}^{2}+\beta_{\mathrm{I}} \sigma_{\mathrm{t}-\mathrm{I}}^{2}
$$

GARCH model is symmetric in modeling conditional volatility. To model asymmetric properties of asset returns volatility the GJR-GARCH model, the EGARCH model and the APARCH models are most popular.

GJR-GARCH Model

$$
\sigma_{\mathrm{t}}^{2}=\alpha_{0}+\alpha_{\mathrm{I}} \varepsilon_{\mathrm{t}-\mathrm{I}}+\lambda_{\mathrm{I}} d_{\mathrm{t}-\mathrm{I}} \varepsilon_{\mathrm{t}-\mathrm{I}}^{2}+\beta_{\mathrm{I}} \sigma_{\mathrm{t}-\mathrm{I}}^{2}
$$

Exponential GARCH(EGARCH) Model

$$
\log \left(\sigma_{\mathrm{t}}^{2}\right)=\alpha_{0}+\alpha_{\mathrm{I}} \varepsilon_{\mathrm{t}-\mathrm{I}}+\lambda_{\mathrm{I}}\left(\left|\varepsilon_{\mathrm{t}-\mathrm{I}}\right|-\mathrm{E}\left|\varepsilon_{\mathrm{t}-\mathrm{I}}\right|\right)+\beta_{\mathrm{I}} \log \left(\sigma_{\mathrm{t}-\mathrm{I}}^{2}\right)
$$

APARCH model

$$
\sigma_{\mathrm{t}}^{\delta}=\alpha_{0}+\alpha_{\mathrm{I}}\left(\left|\varepsilon_{\mathrm{t}-\mathrm{I}}\right|-\lambda \varepsilon_{\mathrm{t}-\mathrm{I}}\right)^{\delta}+\beta_{\mathrm{I}} \sigma_{\mathrm{t}-\mathrm{I}}^{\delta}
$$

Where, parameter $\delta(\delta<0)$ plays the role of a Box-Cox transformation of the conditional standard deviation $\sigma_{\mathrm{t}}$, while $\lambda$ reflects the leverage effect.

\section{Preliminary Analysis}

Table I. Important descriptive statistics of Sensex over the period January I99I to December 2019

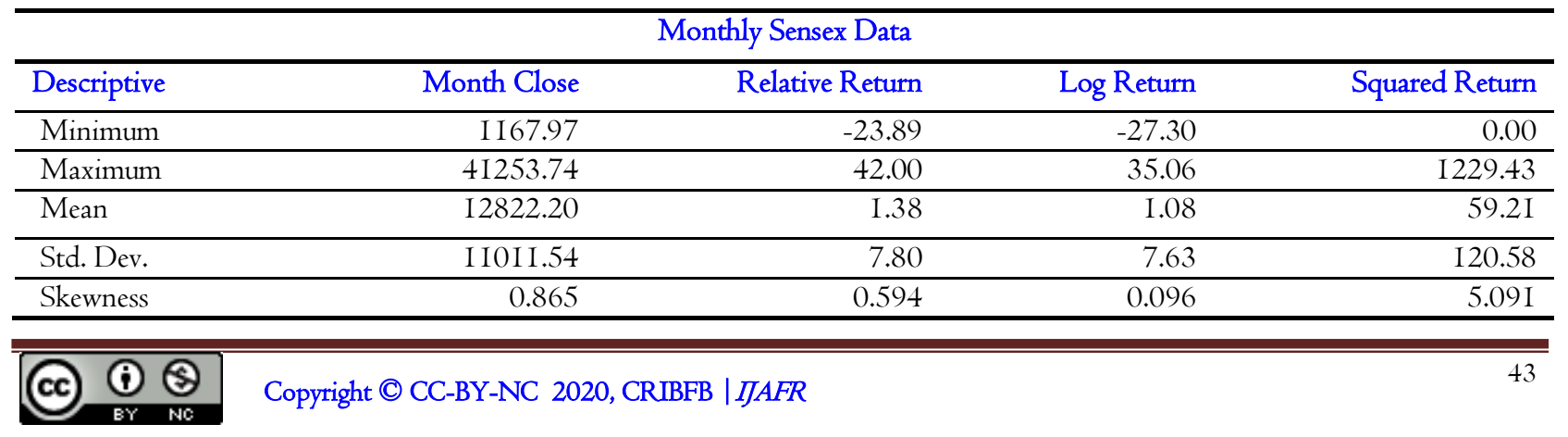




\begin{tabular}{lrrrr}
\hline Kurtosis & 2.572 & 6.109 & 5.167 & 37.430 \\
\hline Jarque-Bera & 0.00 & 0.00 & 0.00 \\
\hline $\mathrm{Q}(\mathrm{I} 0)$ & $\mathrm{I} 2.47(0.25)$ & $\mathrm{II} .04(0.35)$ & $87.66(0.00)$ \\
\hline $\mathrm{Q}(20)$ & $23.4 \mathrm{I}(0.27)$ & $23.5 \mathrm{I}(0.26)$ & $\mathrm{I} 20.83(0.00)$ \\
\hline $\mathrm{ADF}$ & $-\mathrm{I} 6.90(0.00)$ & $-\mathrm{I} 707(0.00)$ & $-\mathrm{I} 4.98(0.00)$ \\
\hline $\mathrm{DF}-$ GLS & -4.97 & -5.84 & $-4.7 \mathrm{I}$ \\
\hline Observations & 347 & 347 & 347 \\
\hline
\end{tabular}

Table I reports descriptive statistics of Sensex close price, relative return, log return, and squared log return. During the study period (I99I-2019, 348 observations) Sensex has highest close of 4I,253.74 points and lowest close of I,I67.97 points with an average of $12,822.20$ points. For the same period the relative return has highest monthly return of 42 percent and lowest return of -23.89 percent. Similarly, Log return has highest return of 35.06 percent and lowest monthly return of -27.30 percent. The average monthly return of relative return is 1.38 percent and log return is 1.08 percent. On the other side volatility of $\log$ returns $(5.17 \%)$ is comparatively lower than the volatility of relative returns $(6.1 \mathrm{I} \%)$. The sample kurtosis of relative return and $\log$ return is greater than 3 and indicates that returns series has excess kurtosis. However, the excess kurtosis of relative return series is 3 and for log return series is 2 . This result is similar to the weaker leptokurtosis report by Schrimpf (2010). Excess kurtosis in relative return and log return postulates that the unconditional distribution of Sensex return series is asymmetric. In addition, Skewness of relative return is 0.59 and $\log$ return is 0.09 . Excess Skewness is observed for the relative return and near to zero Skewness for log return leading to high Jarque-Bera statistics indicating non-normality of the returns series. The J-B test of normality relying on excess kurtosis and Skewness, confirms rejection of null hypothesis for both the series at I percent level of significance. These results indicate that Sensex returns are significantly different from a normal distribution.

The results of Augmented Dickey-Fuller (ADF) and Dickey-Fuller - Generalized Least Squares (DF-GLS) tests reject the unit root hypothesis at the I percent significance level which indicates that the relative return and log return series are stationary. The sample autocorrelation function (ACF) of the squared log returns has high value for the $\mathrm{Q}(\mathrm{I} 0)=87.66(p=$ $0.00)$ and $\mathrm{Q}(20)=120.83(p=0.00)$ test. The slow decay of ACF of the squared log returns suggests that GARCH models may be appropriate to fit the conditional variance.

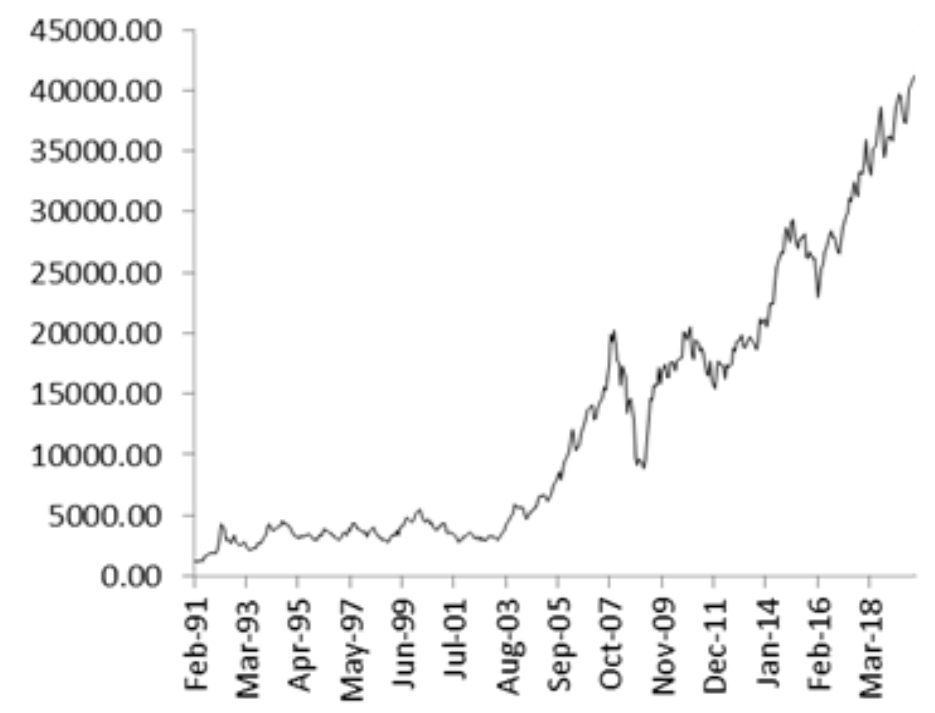

Figure I. Time series plot of Sensex monthly close values over the period January I99I to December 2019

Figure I shows the time series plot of Sensex monthly close values over the period January I99I to December 2019. From the time series plot it is evident that for most of the times, the Sensex has upward trend. In contrast to upward trend, during the period from December 2007 (20,286.99 points) to March 2009 (9,708.50 points) the Sensex tumble continuously for 15 months with a steep loss of 52 percent. This down trend is akin to global turmoil witness by all major economies across the world. Similarly, during December 2010 (20,509.09) to December 2011 (I5,454.92) the Sensex experience downward trend. However, when compared to 2008 downturn, this is lower with a dent of 25 percent in Sensex value. 


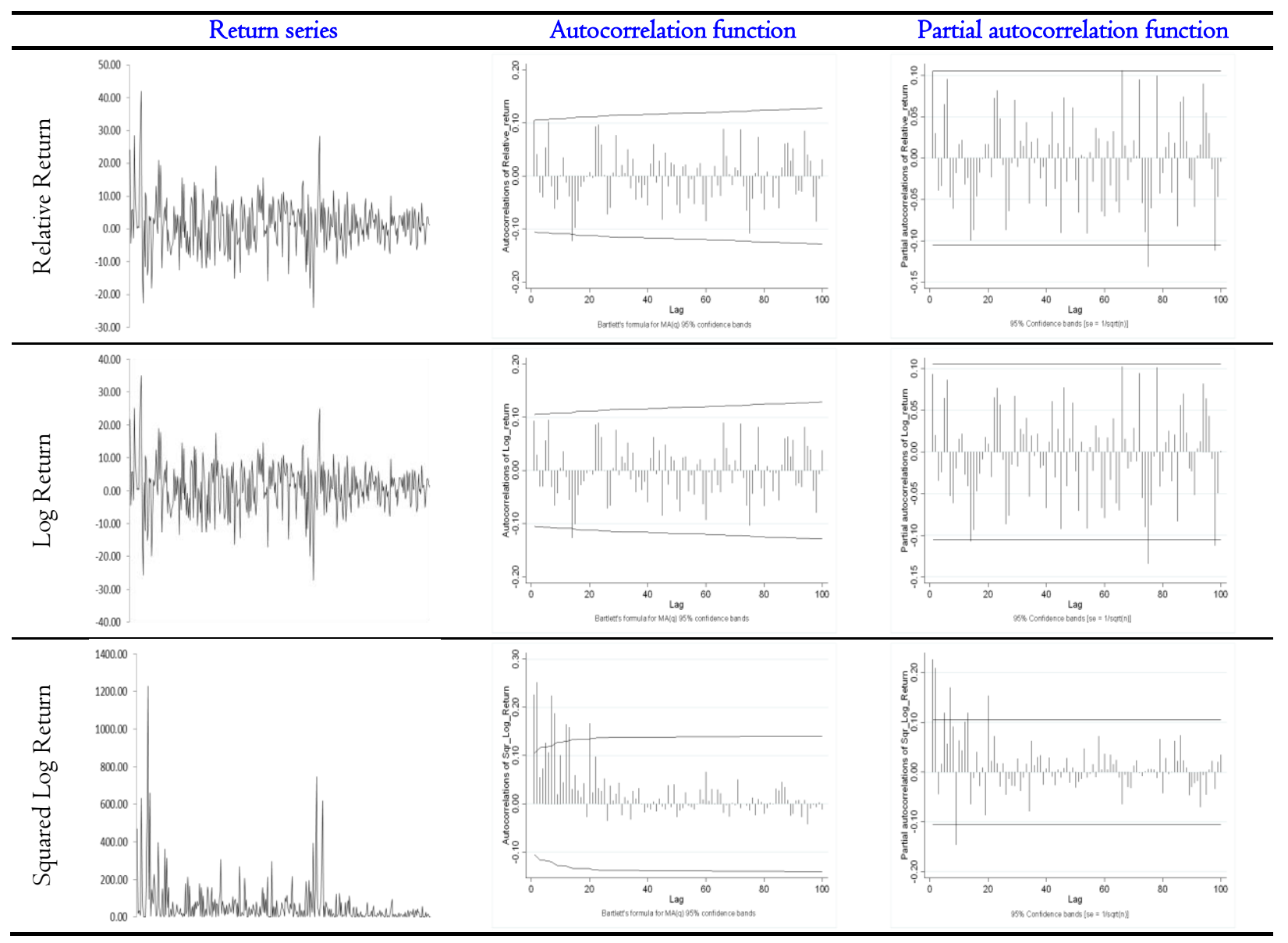

Figure 2. Time series plots of return series, autocorrelation function and partial autocorrelation function

Figure 2 presents return series, autocorrelation function and partial autocorrelation function plots of relative return, $\log$ return, and squared log returns. The relative return and log return series plots indicate no significant autocorrelations or partial autocorrelations. However, in the squared log returns plots the return series has slow decay and there is a presence of significant autocorrelations and partial autocorrelations, suggesting that GARCH models may be appropriate to model the conditional volatility of Sensex monthly returns series.

\section{Empirical Analysis}

In this paper, to model conditional volatility of Sensex monthly log returns series we apply conventional symmetric model and three asymmetric GARCH models under three different distribution densities. To test serial correlations and GARCH effects we form Ljung-Box $Q$-statistics of 5, I0, and 20 lag lengths for standardized residuals and squared standardized residuals. To assess model fit, model adequacy, and select the best fit model we use AIC and BIC information criterion. Empirical results of our data are present in Table 2 and Table 3.

Table 2. Parameter estimates of GARCH (I,I) and GJR-GARCH (I,I) model specifications

\begin{tabular}{|c|c|c|c|c|c|c|}
\hline \multirow[t]{2}{*}{ Parameter } & \multicolumn{3}{|c|}{ GARCH } & \multicolumn{3}{|c|}{ GJR-GARCH } \\
\hline & $\bar{N}$ & $\mathrm{t}$ & GED & $\bar{N}$ & $\overline{\mathrm{T}}$ & GED \\
\hline$\alpha_{0}$ & 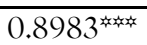 & 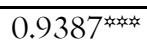 & 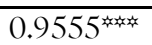 & 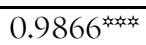 & I.0061 & 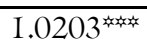 \\
\hline & $(0.3 \mathrm{I} 35)$ & $(0.3 \mathrm{I} 64)$ & $(0.3158)$ & $(0.3200)$ & $(0.32 \mathrm{I} 6)$ & $(0.3204)$ \\
\hline
\end{tabular}




\begin{tabular}{|c|c|c|c|c|c|c|}
\hline$\alpha_{\mathrm{I}}$ & $0.1009^{2}$ & 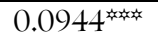 & $0.095 I^{2}$ & $0.0781^{1}$ & $0.074^{2}$ & $0.0745^{\text {站 }}$ \\
\hline & $(0.0262)$ & $(0.028 \mathrm{I})$ & $(0.0290)$ & $(0.0277)$ & $0.0308)$ & $(0.03 \mathrm{I} 3)$ \\
\hline \multirow[t]{2}{*}{$\beta_{\text {I }}$} & 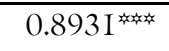 & $0.8983^{2}$ & $0.8980^{2}$ & 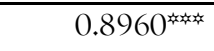 & $0.9002^{x}$ & 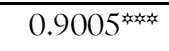 \\
\hline & $(0.0276)$ & $(0.0299)$ & $(0.0307)$ & $(0.0269)$ & $(0.029)$ & $(0.0298)$ \\
\hline \multirow[t]{2}{*}{$\bar{\lambda}$} & - & - & - & 0.0399 & 0.038 & 0.0368 \\
\hline & & & & $(0.036)$ & $(0.0376)$ & $(0.0391)$ \\
\hline \multirow[t]{2}{*}{ V } & - & 3.32 & 1.75 & - & 3.62 & 1.78 \\
\hline & & $(2.26)$ & $(0.2445)$ & & $(2.862)$ & $(0.2486)$ \\
\hline $\log (\mathrm{L})$ & -II6I.72 & -I I6I.52 & -II6I.I4 & -I I6I.I6 & -II6I.05 & -I I60.7 I \\
\hline \multicolumn{7}{|l|}{ Diagnostic Checking } \\
\hline \multicolumn{7}{|l|}{ Standardized Residuals } \\
\hline $\mathrm{Q}(5) \mathrm{p}$ value in parentheses & $1.35(0.93)$ & $\begin{array}{r}1.38 \\
(0.92)\end{array}$ & $\begin{array}{r}1.37 \\
(0.93)\end{array}$ & I.I7 (0.95) & I.I9 $(0.95)$ & $1.20(0.94)$ \\
\hline $\begin{array}{l}\mathrm{Q}(\mathrm{I} 0) \quad \mathrm{p} \text { value in } \\
\text { parentheses }\end{array}$ & $5.39(0.86)$ & $\begin{array}{r}5.35 \\
(0.87)\end{array}$ & $\begin{array}{r}5.35 \\
(0.87)\end{array}$ & $5.15(0.88)$ & $5 . \mathrm{II}(0.88)$ & $5.12(0.88)$ \\
\hline $\begin{array}{l}\mathrm{Q}(20) \quad \mathrm{P} \text { value in } \\
\text { parentheses }\end{array}$ & $\begin{array}{l}\mathrm{I} 2.4 \mathrm{I} \\
(0.90)\end{array}$ & $\begin{array}{l}12.30 \\
(0.90)\end{array}$ & $\begin{array}{l}\mathrm{I} 2.28 \\
(0.9 \mathrm{I})\end{array}$ & $\mathrm{I} 2.20(0.9 \mathrm{I})$ & $\begin{array}{l}\mathrm{I} 2.08 \\
(0.9 \mathrm{I})\end{array}$ & $\begin{array}{l}\mathrm{I} 2.07 \\
(0.9 \mathrm{I})\end{array}$ \\
\hline \multicolumn{7}{|l|}{ Sqrd Standardized Residuals } \\
\hline $\mathrm{Q}(5) \mathrm{p}$ value in parentheses & $5.49(0.36)$ & $\begin{array}{r}5.27 \\
(0.38)\end{array}$ & $\begin{array}{r}5.3 \mathrm{I} \\
(0.38)\end{array}$ & $4.88(0.43)$ & $4.72(0.45)$ & $4.75(0.45)$ \\
\hline $\begin{array}{l}\mathrm{Q}(\mathrm{IO}) \quad \mathrm{P} \text { value in } \\
\text { parentheses }\end{array}$ & $\begin{array}{l}\text { I I.30 } \\
(0.33)\end{array}$ & $\begin{array}{l}\text { II.40 } \\
(0.33)\end{array}$ & $\begin{array}{l}\text { I I.38 } \\
(0.33)\end{array}$ & $\mathrm{I} 0.74(0.38)$ & $\begin{array}{l}\text { I0.9I } \\
(0.36)\end{array}$ & $\begin{array}{l}10.92 \\
(0.36)\end{array}$ \\
\hline $\begin{array}{l}\mathrm{Q}(20) \quad \mathrm{P} \text { value in } \\
\text { parentheses }\end{array}$ & $\begin{array}{l}22.97 \\
(0.29)\end{array}$ & $\begin{array}{l}22.99 \\
(0.29)\end{array}$ & $\begin{array}{l}22.95 \\
(0.29)\end{array}$ & $22.60(0.3 I)$ & $\begin{array}{l}22.7 \mathrm{I} \\
(0.30)\end{array}$ & $\begin{array}{l}22.7 \mathrm{I} \\
(0.30)\end{array}$ \\
\hline \multicolumn{7}{|l|}{ Information Criteria } \\
\hline $\mathrm{AIC}$ & $\begin{array}{r}2331.45 \\
(\mathrm{df} 4)\end{array}$ & $\begin{array}{r}2333.04 \\
(\mathrm{df} 5)\end{array}$ & $\begin{array}{r}2332.29 \\
(\text { df } 5)\end{array}$ & $2332.33(\mathrm{df} 5)$ & $\begin{array}{r}2334.10 \\
(\mathrm{df} 6)\end{array}$ & $\begin{array}{r}2333.42 \\
(\text { df } 6)\end{array}$ \\
\hline $\mathrm{BIC}$ & $\begin{array}{r}2346.84 \\
(\mathrm{df} 4)\end{array}$ & $\begin{array}{r}2352.29 \\
(\text { df } 5)\end{array}$ & $\begin{array}{r}235 \mathrm{I} .53 \\
(\mathrm{df} 5)\end{array}$ & $235 \mathrm{I} .58(\mathrm{df} 5)$ & $\begin{array}{r}2357.20 \\
(\mathrm{df} 6)\end{array}$ & $\begin{array}{r}2356.52 \\
(\mathrm{df} 6)\end{array}$ \\
\hline OBS & 347 & 347 & 347 & 347 & 347 & 347 \\
\hline
\end{tabular}

significant at $1 \%$ level, ${ }^{*}$ significant at $5 \%$ level, significant at 10\% level. In parameter estimates values in parentheses are standard errors.

AIC - Akaike's Information criterion and BIC - Bayesian Information Criterion, OBS - Number of monthly observations 
From results present in Table 2 , it is visible that for the GARCH model with three different distributions $\alpha_{0}$ is positive and $\alpha_{\mathrm{I}}+\beta_{\mathrm{I}}$ is closer to I. The GARCH equation has statistically significant positive short-run and long-run values with low standard error values. The standard errors of $\alpha_{0}$ under all the distributions are very close and are around 0.3I. Similarly, the standard errors of the parameters in the volatility equation are around 0.02 . The residuals series looks like a white noise process at one percent significance level. For the Gaussian distribution we have $Q(5)=1.35(0.93), Q(10)=5.39(0.86)$, and $Q(20)$ $=\mathrm{I} 2.4 \mathrm{I}(0.90)$ for standardized residuals series indicating no serial correlation and $Q(5)=5.49(0.36), Q(\mathrm{I} 0)=\mathrm{II} .30(0.33)$, and $Q(20)=22.97(0.29)$ for squared standardized residuals series, where the number in parentheses is the $p$ value of the test statistic indicating that there is no conditional heteroscedasticity. We notice similar Ljung-Box $Q$-Statistics for student's $t$ distribution and GED distribution. The Q-Statistics of 5, I0, and 20 lag lengths under three distributions are alike with slight deviations. The $Q$-Statistics values of standardized residuals and squared standardized residuals under three distributions are insignificant at conventional levels, so, we can accept the null hypothesis of no remaining serial correlations and no remaining GARCH effects. Thus the GARCH model under three different distribution densities appears to be adequate in describing the linear dependence in the return and volatility series. Given the coefficients $\left(\alpha_{I}\right.$ and $\left.\beta_{I}\right)$ of the GARCH model sum to nearly one $(0.1009+0.893 \mathrm{I}=0.994)$, the conditional volatility is highly persistent.

Finally, the log likelihood values of all the three distributions are -II6I -ignoring decimal values, and there is slight variance in AIC and BIC values. The AIC and BIC select the GARCH (I,I) model under Gaussian distribution over the other two distribution models. For the GARCH (I,I) model with Gaussian distribution, the AIC is 233I.45 and the BIC is 2346.84 . For the Student's $t$-distribution, the AIC is 2333.04 and the BIC is 2352.29. For the GED, the AIC is 2332.96 and the BIC is 235I.53. Results indicate that GARCH (I,I) model under Gaussian distribution captures conditional volatility in Sensex monthly return better than that of GARCH $(\mathrm{I}, \mathrm{I})$ model under student's $t$-distribution and GED.

Table 3. Parameter estimates of EGARCH $(\mathrm{I}, \mathrm{I})$ and $\mathrm{APARCH}(\mathrm{I}, \mathrm{I})$ model specifications

\begin{tabular}{|c|c|c|c|c|c|c|}
\hline \multirow[t]{2}{*}{ Parameter } & \multicolumn{3}{|c|}{ EGARCH } & \multicolumn{3}{|c|}{ APGARCH } \\
\hline & $\mathrm{N}$ & $\mathrm{t}$ & GED & $\mathrm{N}$ & $\mathrm{T}$ & GED \\
\hline \multirow[t]{2}{*}{$\alpha_{0}$} & $1.0594^{\text {and }}$ & 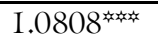 & $1.0825^{x}$ & I.0I46 & $1.0515^{2}$ & I.05II \\
\hline & $(0.319 \mathrm{I})$ & $(0.3195)$ & $(0.3182)$ & $(0.3243)$ & $(0.3246)$ & $(0.3230)$ \\
\hline \multirow[t]{2}{*}{$\alpha_{\text {I }}$} & $0.1859^{2}$ & $0.1634^{\text {and }}$ & $0.173 I^{2}$ & $0.0987^{2}$ & 0.0879 & $0.0921^{1}$ \\
\hline & $(0.0457)$ & $(0.0545)$ & $(0.054 \mathrm{I})$ & $(0.0296)$ & $(0.0299)$ & $(0.0312)$ \\
\hline \multirow[t]{2}{*}{$\beta_{\text {I }}$} & $0.9918^{x}$ & $0.992 I^{x}$ & 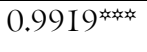 & 0.9069 & $0.9197^{2 x+x}$ & $0.915 I^{2}$ \\
\hline & $(0.0128)$ & $(0.0127)$ & $(0.0136)$ & $(0.0254)$ & $(0.0277)$ & $(0.028 \mathrm{I})$ \\
\hline \multirow[t]{2}{*}{$\lambda$} & $0.0416^{\text {tx }}$ & 0.04 & 0.0394 & 0.1512 & 0.1942 & 0.1701 \\
\hline & $(0.0229)$ & $(0.025)$ & $(0.0257)$ & $(0.1284)$ & $(0.178 I)$ & (0.1633) \\
\hline \multirow[t]{2}{*}{$\bar{v}$} & - & 2.98 & 1.74 & - & 3.16 & 1.76 \\
\hline & & (I.5I9I) & $(0.2305)$ & & $(1.8405)$ & $(0.2407)$ \\
\hline \multirow[t]{2}{*}{ Power } & & & & $1.555^{2}$ & $1.35^{\text {乘新 }}$ & $1.42^{x+2 x}$ \\
\hline & & & & $(0.6987)$ & $(0.6869)$ & $(0.7375)$ \\
\hline $\log (\mathrm{L})$ & -II6I.4I & -II 60.97 & -I I60.7 I & -I I6I.2I & -II 60.95 & -I I60.64 \\
\hline
\end{tabular}

Diagnostic

Checking

Standardized 


\begin{tabular}{|c|c|c|c|c|c|c|}
\hline Residuals & & & & & & \\
\hline $\begin{array}{l}Q(5) p \text { value in } \\
\text { parentheses }\end{array}$ & $1.45(0.90)$ & $1.47(0.92)$ & $1.48(0.92)$ & $1.26(0.94)$ & $\begin{array}{r}\mathrm{I} .34 \\
(0.93)\end{array}$ & $1.32(0.93)$ \\
\hline $\begin{array}{l}\mathrm{Q}(\mathrm{I} 0) \mathrm{p} \text { value in } \\
\text { parentheses }\end{array}$ & $5.10(0.89)$ & $4.96(0.89)$ & $5.02(0.89)$ & $5.06(0.89)$ & $\begin{array}{r}4.93 \\
(0.89)\end{array}$ & $4.99(0.89)$ \\
\hline $\begin{array}{l}\mathrm{Q}(20) \mathrm{p} \text { value in } \\
\text { parentheses }\end{array}$ & $\mathrm{I} 2.50(0.90)$ & $\begin{array}{l}\mathrm{I} 2.28 \\
(0.9 \mathrm{I})\end{array}$ & $\begin{array}{l}\mathrm{I} 2.38 \\
(0.90)\end{array}$ & $\begin{array}{l}\mathrm{I} 2.22 \\
(0.9 \mathrm{I})\end{array}$ & $\begin{array}{l}\mathrm{I} 2.04 \\
(0.9 \mathrm{I})\end{array}$ & $\mathrm{I} 2 . \mathrm{I0}(0.9 \mathrm{I})$ \\
\hline \multicolumn{7}{|l|}{$\begin{array}{l}\text { Sqrd } \\
\text { Standardized } \\
\text { Residuals }\end{array}$} \\
\hline $\begin{array}{l}Q(5) p \text { value in } \\
\text { parentheses }\end{array}$ & $4.16(0.53)$ & $4.19(0.52)$ & $4.17(0.52)$ & $4.49(0.48)$ & $\begin{array}{r}4.18 \\
(0.52)\end{array}$ & $4.27(0.5 \mathrm{I})$ \\
\hline $\begin{array}{l}\mathrm{Q}(\mathrm{I} 0) \mathrm{p} \text { value in } \\
\text { parentheses }\end{array}$ & I I.32(0.33) & $\begin{array}{l}\mathrm{I} 2.5 \mathrm{I} \\
(0.25)\end{array}$ & $\begin{array}{l}\text { I I.95 } \\
(0.29)\end{array}$ & $\begin{array}{l}\text { I I.05 } \\
(0.35)\end{array}$ & $\begin{array}{l}\text { II.99 } \\
(0.29)\end{array}$ & I I.56 (0.32) \\
\hline $\begin{array}{l}\mathrm{Q}(20) \mathrm{p} \text { value in } \\
\text { parentheses }\end{array}$ & $23.22(0.28)$ & $\begin{array}{l}24.19 \\
(0.23)\end{array}$ & $\begin{array}{l}23.73 \\
(0.25)\end{array}$ & $\begin{array}{l}22.85 \\
(0.30)\end{array}$ & $\begin{array}{l}23.61 \\
(0.26)\end{array}$ & $23.25(0.28)$ \\
\hline \multicolumn{7}{|l|}{$\begin{array}{l}\text { Information } \\
\text { Criteria }\end{array}$} \\
\hline $\mathrm{AIC}$ & $\begin{array}{r}2332.82(\mathrm{df} \\
5)\end{array}$ & $\begin{array}{r}2333.94 \\
(\mathrm{df} 6)\end{array}$ & $\begin{array}{r}2333.43 \\
(\text { df } 6)\end{array}$ & $\begin{array}{r}2334.42 \\
(\mathrm{df} 6)\end{array}$ & $\begin{array}{r}2335.90 \\
(\mathrm{df} 7)\end{array}$ & $\begin{array}{r}2335.29(\mathrm{df} \\
7)\end{array}$ \\
\hline $\mathrm{BIC}$ & $\begin{array}{r}2352.07(\mathrm{df} \\
5)\end{array}$ & $\begin{array}{r}2357.04 \\
(\text { df } 6)\end{array}$ & $\begin{array}{r}2356.52 \\
(\mathrm{df} 6)\end{array}$ & $\begin{array}{r}2357.51 \\
(\text { df } 6)\end{array}$ & $\begin{array}{r}2362.84 \\
(\mathrm{df} 7)\end{array}$ & $\begin{array}{r}2362.23(\mathrm{df} \\
7)\end{array}$ \\
\hline OBS & 347 & 347 & 347 & 347 & 347 & 347 \\
\hline
\end{tabular}

We then proceed to estimate the conditional variance of Sensex with the following asymmetric models, GJR-GARCH model, EGARCH model, and APARCH model under three different distributions using maximum likelihood method. The coefficients of estimated models, their log likelihood ratios, diagnostic tests result, and the information criterion values are present in Table 3. In all the three asymmetric models under different distributions the GARCH coefficients are positive and statistically significant at I percent significance level.

The estimated parameters for GJR-GARCH model indicate that the coefficients of ARCH $\left(\alpha_{\mathrm{I}}=0.07\right)$ and GARCH $\left(\beta_{\mathrm{I}}=0.89\right)$ in the conditional variance equation are statistically significant at I per cent level for all distribution densities. Next, the estimated coefficients of ARCH $\left(\alpha_{\mathrm{I}}=0.19\right)$ and $\mathrm{GARCH}\left(\beta_{\mathrm{I}}=0.99\right)$ for EGARCH and similarly, ARCH $(\boldsymbol{\alpha} \mathrm{I}=0.09)$ and GARCH $\left(\beta_{\mathrm{I}}=0.90\right)$ for APARCH for all distribution densities are statistically significant at I percent level. We observe leverage effect only in GJR-GARCH model under Gaussian distribution. The leverage, $\lambda$ coefficient in GJR-GARCH model is positive for all distributions, however, statistically not significant. The evidence shows that news impact is asymmetric in Sensex as $\lambda \neq 0$ for EGARCH under Gaussian distribution, with statistically significant coefficient at I0 percent level. The EGARCH model captures asymmetric effect. In contrast, the other two asymmetric models under all three distribution densities have insignificant $\lambda$ values. The $\lambda$ coefficient in GJR-GARCH model and APARCH model is positive but statistically insignificant for all the three distributions. The diagnostics tests of asymmetric GARCH models seem to be satisfactory. Also, the results from the models show that $Q$-statistics for the standardized residuals and squared standardized residuals are insignificant with high $p$-values. 
From results we observe that GJR-GARCH model, EGARCH model, and APARCH model have the largest log likelihood values (-I I60) with GED distribution. Using the standardized residuals, for GJR-GARCH model with Gaussian distribution we obtain $\mathrm{Q}(5)=\mathrm{I} . \mathrm{I} 7(0.95), \mathrm{Q}(\mathrm{IO})=5 . \mathrm{I} 5(0.88)$, and $\mathrm{Q}(20)=\mathrm{I} 2.20(0.9 \mathrm{I})$ where the $p$ values are in parentheses. For EGARCH model with Gaussian distribution we obtain $\mathrm{Q}(5)=\mathrm{I} .45(0.90), \mathrm{Q}(\mathrm{I0})=5.10(0.89)$, and $\mathrm{Q}(20)$ $=\mathrm{I} 2.50$ (0.90). Similarly for APARCH model with Gaussian distribution we obtain $\mathrm{Q}(5)=\mathrm{I} .26(0.94)$ and $\mathrm{Q}(\mathrm{I0})=5.08$ $(0.89)$, and $\mathrm{Q}(20)=\mathrm{I} 2.22(0.9 \mathrm{I})$. From these results we conclude that there are no serial correlations in the residuals of the fitted models.

We also examine the presence of remaining GARCH effects using the Ljung-Box Q-statistics of the squared standardized residuals series. For GJR-GARCH model with Gaussian distribution show $\mathrm{Q}(5)=4.88(0.43), \mathrm{Q}(\mathrm{I0})=\mathrm{IO} .74$ $(0.38)$, and $\mathrm{Q}(20)=22.60(0.3 \mathrm{I})$ where the $p$ values are in parentheses. For EGARCH model with Gaussian distribution we obtain $\mathrm{Q}(5)=4 . \mathrm{I} 6(0.53), \mathrm{Q}(\mathrm{I0})=\mathrm{I}$ I.32 (0.33), and $\mathrm{Q}(20)=23.22(0.28)$. Similarly for APARCH model with Gaussian distribution we obtain $\mathrm{Q}(5)=4.49(0.48)$ and $\mathrm{Q}(\mathrm{IO})=\mathrm{II} .05(0.35)$, and $\mathrm{Q}(20)=22.85(0.30)$. These results indicate that the standardized residuals have no conditional heteroscedasticity. The fitted model seems adequate at one percent significance level.

We notice variations in AIC and BIC values. The AIC and BIC select the GIR-GARCH (I,I) model, EGARCH (I,I) model, and APARCH (I,I) model under Gaussian distribution over the other two distribution models. For the GJR-GARCH (I,I) model with Gaussian distribution, the AIC is 2332.33 and the BIC is 235I.58. For the EGARCH (I,I) model with Gaussian distribution, the AIC is 2332.82 and the BIC is 2352.07. For the APARCH (I,I) model, the AIC is 2334.42 and the BIC is 2357.5I. Results indicate that asymmetric GARCH models under Gaussian distribution captures conditional volatility in Sensex monthly return better than under student's $t$-distribution and GED.

When we compare efficiency of symmetric and asymmetric models using information criteria, we notice that conventional GARCH (I,I) model has better AIC and BIC values. In asymmetric GARCH models GJR-GARCH model has better information criteria values. However, it's the EGARCH model with Gaussian distribution that capture the leverage effect in the Sensex monthly returns series. Moreover, a comparison of 12 models under different distribution densities indicate that both symmetric and asymmetric GARCH models under Gaussian distribution clearly outperforms the GARCH models under student's $t$-distribution and GED distribution.

\section{Conclusion}

The aim of this paper is to characterize volatility models by their ability to capture commonly held stylized facts about conditional volatility. We consider 29 years of post-liberalization period in India. The time period spans from January I99I to December 2019. We obtain monthly close values of Sensex and calculate returns series. We estimate GARCH (I,I), GJRGARCH (I,I), EGARCH (I,I), and APARCH (I,I) models under three most commonly used distribution densities, the Gaussian, Student's $t$-distribution and GED distribution for a total of 12 models. The Sensex monthly returns series exhibit positive Skewness, weaker excess kurtosis and no serial correlations. These results are similar to the results report by(Pagan, 1996; Cont, 2001) who report that low frequency returns series such as monthly returns tend to have normal distribution properties. The squared log returns series has significant autocorrelation and squared returns decay slowly indicating presence of volatility clustering. This result is similar to results report by (Ding et al., I993; Ding \& Granger, I996; McMillan \& Ruiz, 2009) who report slow decay of the autocorrelations of squared and absolute returns over time. We conclude that GARCH $(\mathrm{I}, \mathrm{I})$ model under Gaussian distribution captures conditional volatility adequately in Sensex monthly return better than that of GARCH (I,I) model under student's $t$-distribution and GED. Similarly, the GJR-GARCH (I,I) model, EGARCH (I,I) model, and APARCH (I,I) model under Gaussian distribution captures conditional volatility adequately over the other two distribution models. Furthermore, conventional GARCH (I,I) model has better AIC and BIC values over GJR-GARCH (I,I) model, EGARCH (I,I) model, and APARCH (I,I). Among asymmetric GARCH models GJR-GARCH model has better information criteria values. Finally, GJR-GARCH (I,I) model under Gaussian distribution exhibit significant leverage effect. In contrast, the other two asymmetric models under all three different distribution densities have in significant $\lambda$ values.

\section{References}

Akaike, H. (1974). A new look at the statistical model identification. IEEE Transactions on Automatic Control, I9(6), 7I6723.

Bollerslev, T. (I986). Generalized autoregressive conditional heteroskedasticity. Joumal of econometrics, 3I(3), 307-327.

Cont, R. (200I). Empirical Properties of Asset Returns: Stylized Facts and Statistical Issues. Quantitative Finance, I, $223-236$.

Ding, Z., Granger, C. W., \& Engle, R. F. (I993). A long memory property of stock market returns and a new model. Journal of empirical finance, $I(\mathrm{I}), 83-\mathrm{I} 06$.

Ding, Z., \& Granger, C. W. (1996). Modeling volatility persistence of speculative returns: a new approach. Journal of econometrics, 73(I), I85-2I5. 
Glosten, L. R., Jagannathan, R., \& Runkle, D. E. (I993). On the relation between the expected value and the volatility of the nominal excess return on stocks. The journal of finance, 48(5), I779-I80I.

Joshi, P. (20I4). Forecasting Volatility of Bombay Stock Exchange. International journal of current research and academic review, 2(7), 222-230.

Karmakar, M. (2007). Asymmetric volatility and risk-return relationship in the Indian stock market. South Asia Economic Journal, 8(I), 99-II6.

McMillan, D. G., \& Ruiz, I. (2009). Volatility persistence, long memory and time-varying unconditional mean: Evidence from I0 equity indices. The Quarterly Review of Economics and Finance, 49(2), 578-595.

Mittal, A. K., Arora, D. D., \& Goyal, N. (2012). Modeling the volatility of Indian stock market. gitam Journal of Management, IO(I), 224-43.

Nelson, D. B. (199I). Conditional heteroskedasticity in asset returns: A new approach. Econometrica: Journal of the Econometric Society, 59(2), 347-370.

Pagan, A. (1996). The econometrics of financial markets. Journal of empirical finance, 3(I), I5-I02.

Schrimpf, A. (2010). International stock return predictability under model uncertainty. Journal of International Money and Finance, 29(7), 1256-1282.

Schwarz, G. (1978). Estimating the dimension of a model. The annals of statistics, 6(2), 46I-464.

\section{Copyrights}

Copyright for this article is retained by the author(s), with first publication rights granted to the journal. This is an open-access article distributed under the terms and conditions of the Creative Commons Attribution license (http://creativecommons.org/licenses/by/4.0/). 